\title{
Libraries as Organizations
}

Following general discussion of organizations and the proper ways of setting, seeking, and attaining organization goals, this paper examines libraries in such a context and makes observations concerning them. It comments upon current developments and problems in libraries viewed in this framework and discusses their relationship to the community and the bibliographic universe. It speculates on appropriate bases for determining their success or failure.

I T IS THE PURPOSE of this paper to explore the possible applications of organization theory to the study of libraries. Schools, prisons, hospitals, employment services, government bureaucracies, factories, mines, advertising agencies, and libraries-these and other organizations like them are the focus of the attention of the student of organizations. Particular organizations of this kind are often called "complex," "formal," or "bureaucratic." They are distinctively created for a purpose. They may wax and wane according to the changing social importance of their objectives and their own efficiency. Yet they emerge from, depend on, and as a totality help provide some kind of structure for the more general social organization which underlies them.

The study of "formal organizations" is at once an offshoot of sociology and something more. Its present character is partly the result of diverse origins and partly of the varied backgrounds in other disciplines that contemporary students bring to bear on it. Its origins date back to nineteenth-century political economy, to Taylorism and management theory, to the study of human relations, and especially to Weberian sociology. It is now

Mr. Rayward is Assistant Professor and Periodicals Librarian in the Chicago State College Library. pursued by scholars with an extraordinary range of interests. In his introduction to the Handbook of Organizations, March classifies the contributors according to the fields in which they received their doctorates. Economics, political science, psychology, and business and industrial administration, as well as sociology, are represented. ${ }^{1}$ An analysis of the papers on organization at the 1964 annual meetings of a number of learned societies in the general area of the social sciences, revealed an even greater interdisciplinary spread. ${ }^{2}$

A formal organization is an organization with "explicit, limited and announced" objectives. ${ }^{3}$ As Blau and Scott explain: "If the accomplishment of an objective requires collective effort, men set up an organization designed to coordinate the activities of many persons and to furnish incentives for others to join them for this purpose."4 Generally speaking, an organization's overall purpose can be achieved only by a factoring of it into "operational" sub-goals, and the pursuit of these through a series of differentiated tasks allocated systematically among the members of the organiza-

${ }^{1}$ Handbook of Organizations, ed. by James G. March (Chicago: Rand McNally, 1965), p. xiv.

${ }^{2}$ Ibid., p. xv.

"Stanley H. Udy, "The Comparative Analysis of Organizations," in Handbook of Organizations, op. cit., p. 678.

4 Peter M. Blau and W. Richard Scott, Formal Organizations (San Francisco: Chandler, 1962), p. 5. 
tion. The tasks employ a changing technology, and this influences and demands change in what can be done and how it can be done. Usually a hierarchy of authority, and with it specified lines of communication, is set up to facilitate the coordination of the various parts of the organization as they interact to achieve the organization's goals. That is to say the creation of any formal organization raises problems of delegation, direction, control, communication, and the assumption and use of authority. These problems increase in complexity as the organization itself increases in size and complexity. But while there is a strong implication of rationality in the structure and process of an organization, such an implication of rationality must be treated with considerable reserve. This is necessary because of the difficulty of defining the objectives of the organization clearly enough to elicit whatever approval is necessary for them to be maintained and met by organizational participants. The members of the organization are at once limited in their abilities to handle information, make decisions, communicate with one another and otherwise to interact fanctionally. They have goals of their ow $n$ which the organization must realize in some degree to secure their satisfaction and to continue their productive participation in it. The individual goals of the members may to a greater or lesser degree conflict with those the organization has set for them. They participate in the organization in one of the many roles they assume as members of society. The role the organization creates for them may be influenced by or come into conflict with their other roles, or be distorted by their participation in the organization as "whole" persons. They form informal groups not corresponding to the formal structural arrangements. Informal group norms and goals gradually emerge and these may be functional or they may be dysfunctional ${ }^{5}$ for the organization as a whole. Over time the organization expands or contracts, changes necessarily ramifying throughout its entire structure and affecting the processes going on within it. To persist and grow it must prove adaptable both to changing social pressures and to technological innovation. It must also prove to be reasonably efficient. Presumably organizational success is determined partly by how well it meets its goals, and partly by how effectively it obtains support for them or is able to permit them to be redefined or shifted as the social wind changes-as they are realized (realization sometimes implying dissolution ${ }^{6}$ ), or become outmoded. That is to say, an organization must have at least two generally adjustive mechanisms. One mediates between society and the organization's formulation of goals (especially necessary if the organization has as its major purpose the provision of services); the other is a mechanism to determine effectiveness of performance. Crudely, "profit" serves both functions in a business organization. The facts of profit (and of loss) initiate various kinds of organizational change-from expansion to dissolution, a process exemplified in Thompson's "history" of the Aardvark Firm (which provides an illustrative setting for various kinds of decision-making strategy). ${ }^{7}$ The first mechanism might be described as ecological and the other as a performance-feedback mechanism.

Some of the general threads of organization theory then recognize that an organization is a goal-directed "organ-

\footnotetext{
5 "Dysfunctional" is a term defined by Robert $\mathrm{K}$. Merton to mean "those observed consequences which lessen the adaptation or adjustment of the system," Social Theory and Social Structure (Glencoe, Illinois: Free Press, 1949), p. 50.

"David L. Sills, "The Succession of Goals," in Complex Organizations, a Sociological Reader, ed. by Amitai Etzioni (N.Y.: Holt, Rinehart and Winston, 1962 ), p. 146-59.

"James D. Thompson, "Decision-making, the Firm and the Market," in New Perspectives in Organizational Research, ed. by William W. Cooper et al. (N.Y.: Wiley, 1964), p. 334-48.
} 
ism," "organism" being explained differently by different theories. It has an environment inter-penetrating it in various ways: in setting limits upon its formulation of goals, in determining the degree of goal achievement, and in bringing various kinds of influence to bear upon its participants. It has input and output, and intermediate between these some kind of process involving formal and informal structures or patterns of consistent relations between participants. It has some sort of technology. A formal structural and procedural rationality is recognized as intrinsic to it, and attempts are made to account for the disruption or modification of this in process. One may account for organizational stability, coherence, and consistency of action in terms of "bureaucratic" rules or in terms of programs for decision-making, and one must account for incoherence, instability, and inconsistency in terms of complex limits set upon these rules or programs.

Much of present-day theory is a matter of points of view, emphases and approaches, which, as they strive for completeness, converge. One may view the organization as a "bureaucracy" (especially if it is a "service" or "commonwealth" organization ${ }^{9}$ ), or as a decision-

\footnotetext{
${ }^{8}$ The classical account of bureaucracy is provided by Max Weber in From Max Weber: Essays in Sociology, tr. by H. H. Gerth and C. Wright Mills (New York: Oxford University Press, 1946). The literature on bureaucracy since then has been extraordinarily voluminous. Among basic works are: Robert K. Merton et al., Reader in Bureaucracy (Glencoe, Illinois: Free Press, 1952), Peter M. Blau, The Dynamics of Bureaucracy (Chicago: University of Chicago Press, 1955), Blau Bureaucracy in Modern Society (New York: Random House, 1956), and Alvin W. Gouldner's Patterns of Industrial Bureaucracy (Glencoe, Illinois: Free Press, 1954).

${ }^{9}$ For Blau and Scott a service organization is "one whose prime beneficiary is the part of the public in direct contact with the organization, with whom and on whom its members work. . . e.g., schools, hospitals, legal-aid societies, etc. (Formal Organizations, op. cit., p. 51). Commonwealth organizations have the "distinctive characteristic ... that the public-at-large is their prime beneficiary, often, although not necessarily, to the exclusion of the very people who are the object of the organization's endeavor," e.g., Bureau of Internal Revenue, military and police services, and the research as opposed to the teaching function of universities, etc. (Formal Organizations, op. cit., p. 54).
}

making system ${ }^{10}$; or from the point of view of the management expert concerned with efficiency and limited by notions of rationality; or of the psychologist for whom an organization is a complex but relatively stable set of personal or role relations, affecting and affected by other aspects of personality, motivation, and perception of the individuals in an organization; ${ }^{11}$ or of the sociologist who uses the organization as a social system contributing to and taking from other more pervasive systems; ${ }^{12}$ or of the businessman concerned with profit and loss for whom, ultimately, explanation and understanding must stand the test of operational expedience.

From the general field of formal organizations theory and research, the librarian then may hope for a "scientific" account of the dynamics of formal organizations, and become aware of the many general phenomena of organizations interrelating to affect organizational structure and process. Theory, after all, is a kind of tool which can be brought to bear on particular cases from a number of which it represents systematic abstraction. This tool can be of material assistance in the understanding and direction of libraries as organizations with

${ }^{10}$ The major thesis of James G. March and Herbert Simon's Organizations (New York: Wiley, 1958) is that "the basic features of organizational structure and function derive from the characteristics of human problem solving processes and rational human choice." (p. 169). Chapter 6 of this work "The Cognitive Limits of Rationality" is the basis for a sophistication of this approach. R. M. Cyert and J. G. March view the organization itself as making decisions, as behaving in an "adaptively rational way" to achieve its goals ("The Behavioural Theory of the Firm . . ." in New Perspectives in Organizational Research, op. cit., p. 289-304).

11 Harold J. Leavitt describes this view as a "people approach" in his "Applied Organization Charge in Industry . . ." (in New Perspectives in Organizational Research, op. cit., p. 63-70). The work of Chris Argyris ["Understanding Human Behaviour in Organization" in Modern Organization Theory ed. by Mason Haire (New York: Wiley, 1959), and Personality and Organization (New York: Harper, 1957), for example] is noteworthy in this respect.

12 This view is particularly important to the Structuralist-functionalist school of sociology and is expressed in Talcott Parsons' "Suggestions for a Sociological Approach to the Theory of Formal Organizations" (in Complex Organizations, a Sociological Reader, ed. by Amitai Etzioni, op. cit., p. 35-6). 
"specific, limited and announced" objectives. Not only is it expedient for the librarian to become aware of and apply relevant findings from organizational research, he is himself involved in a theorymaking endeavor similar to that of the organizational theorist. What the librarian wants is a model by which his understanding of the library is adequately represented. Such a model would permit him accurately to anticipate correspondent behavior in various organizational parameters as others are varied either purposefully or under the uncontrollable force of circumstance. With the knowledge obtained from tested prediction he can both refine his model and more intelligently guide the growth and development of his library. This desire of the librarian for a theory which will permit him to work with understanding beyond purely descriptive or prescriptive accounts of library administration and organization sets him shoulder to shoulder with the organization theorist who works at a more general level. In a sense they are indispensable to each other. The librarian's theory must, as it were, be a skeletal part of a more general theory, but fleshed out in a particular way.

\section{Towards an Organizational ANALYSIS OF THE LIBRARY}

A general organizational analysis of the present-day library appropriately may begin with the observation that an important characteristic of the library is that it takes in large quantities of discrete physical items-books, periodicals, manuscripts, phonograph records, music, tapes, and so on (all of which constitute a sampling, often according to specified criteria, of a "bibliographic" universe), subjects them to various processes, stores them, and then provides various kinds of service based on them. It is interesting to draw a parallel with an industrial firm. The firm takes in materials from the environment, processes them to form salable goods of some kind, and then disposes of them in the environment. A complex regulatory cost-price mechanism controls expansion in the firm and changes in its products and management. Always there is turnover, a kind of equilibrium maintained-what goes in must come out. With certain minor exceptions, however, libraries rarely dispose of materials, certainly never at a rate equal to their intake. They are as a result subject to unremitting increment, and inevitably are committed to a methodological conservatism which is much more than the manifestation of dysfunctional bureaucratization. Moreover, the materials used by libraries, of increasing diversity, have continued to be produced for the last 150 years and more, at an ever-accelerating rate-Price's curves of exponential growth in the periodical literature of science, ${ }^{13}$ though perhaps somewhat exaggerated, ${ }^{14}$ are dramatic demonstrations of this. That the rapid "doubling" process is even more general was demonstrated much earlier by Hulme's study of patents, ${ }^{15}$ and by Fremont Rider's analysis of the statistics of growth of certain American university libraries since colonial times. ${ }^{16}$ Research and large public libraries especially not only of necessity grow in size as a function of time, they must grow exponentially in order to keep up with the expanding bibliographic universe they sample. Whether or not they should attempt to do this is a problem of great complexity and interest. $^{17}$

${ }^{13}$ Derek J. de Solla Price, Little Science, Big Science (New York: Columbia University Press, 1965), p. 18, 21.

14 Kenneth O. May, "Quantitive Growth of the Mathematical Literature," Science, CLIV (December 1966 ), p. 1672-3.

${ }^{15}$ E. W. Hulme, Statistical Bibliography . . . (London: The Author, 1923).

16 Fremont Rider, The Scholar and the Future of the Research Library . . . (New York: Hadharn Press, 1944).

${ }_{17}$ An interesting recent discussion of this whole issue is to be found in Margit Kraft's "An Argument for Selectivity in the Acquisition of Materials for Research Libraries," Library Quarterly XXXVII (July 1967), 284-95. 
Growth has far-reaching consequences which must be faced if the library is not to assume the proportion of a contemporary dinosaur. Haire has pointed out the biological parallel in a business firm -that as its size increases, the skeletal structure "needed to support it against the forces tending to destroy it" must grow even faster. ${ }^{18}$ The problem is more complex in the library, given the absence of any significant turnover. The greater the number of materials acquired by the library, the greater the need for a processing which distinguishes between them. The problems of growth are not simply those of greater bulk to be handled and stored; nor is efficiency, given growth, simply a matter of devising better handling and storage techniques-such as the assembly line, or automation, though these may help. As well as quantitative problems, increased size and diversity of collections introduce all kinds of qualitative problems-classification systems break down; descriptive cataloging methods prove inadequate (either in achieving a requisite specificity or because of their slowness); subject indication, increasingly a critical matter in libraries, becomes increasingly difficult, and as its tools become more complex, librarians are more likely to be inadequate to the kinds of specialist demands made upon them. Nor can the library hope for a concomitant increase in the size of its public, and therefore in the basis of its support, for the library is always a part of another organization which provides it with its raison d'être and with financial support. The implications of growth, however, are not always recognized by the institution of which the library is a part. In some quarters, academic libraries, for example, have a reputation for

${ }^{18}$ Maison Haire, "Growth of Organizations," in Modern Organization Theory ed. by Maison Haire, op. cit., p. 275 . being overweening in their pretensions to importance in the academic community, and for wanting more than their share of the university budget. ${ }^{19}$ There is, indeed, a general lack of knowledge about the functions, limitations, needs, and potentialities of the library ${ }^{20}$-after all the client does not die, or lose a fortune, or sue. Nevertheless, much of the recent polemical and hortatory literature of librarianship has come from the pens of various kinds of academics, some familiar with libraries, some not, who have been struck by a kind of "big-bang" theory of the bibliographical universe. With the computer in one hand and in the other an optimism almost naïve considering the history of "panaceatic" bibliography, ${ }^{21}$ they present themselves as able to provide deliverance into efficiency and maximum usefulness of an organization that all recognize as importantso important in its functions indeed, that it must be superseded, or, at least, dramatically transformed if the needs of scholarship generally, of science in particular, of "the community," of "democracy," of the American nation vis-à-vis the threat of a monolithic world communism, are to be met adequately.

Meanwhile the modern library swells perilously but cannot, like a business firm, seek to support its growth by increasing its "market" or its "prices." It is constrained to bargain with the organization of which it is part, but its bargaining power is limited by ignorance and by its own inefficacy-ignorance of what it should be doing, of what it can do best, of how its aims should be met;

19 John D. Millet, Financing Higher Education in the United States (New York: Commission on Financing Higher Education and Columbia University Press, 1952), p. 122-25.

${ }^{20}$ University of Michigan, Survey Research Center, Faculty Appraisal of a University Library (Ann Arbor, Michigan: The University of Michigan Library, 1961). ${ }^{21}$ W. Boyd Rayward, "A History of Systematic Bibliography in England, 1850-1895," Occasional Paper, University of Illinois Graduate School of Library Science, no. 84, June 1967. 
inefficacy at providing indubitably indispensable services. Given the millenia of the history of libraries, and the emergence of a profession of librarianship about a hundred years ago, such dubieties are curious and worthy of the most careful scrutiny. Such a scrutiny must begin by finding out what actually libraries do, and how they do it; and how what is done differs from library to library and from one kind of library to another. In other words, so much speculation and prescription about libraries to such little effect (after all it goes on unabated)show how little is really understood about them. Adequate descriptive accounts will appear only when the library is regarded as a formal organizationwith objectives of varying degrees of specificity and clarity, with a peculiar structure to some degree suited to tasks undertaken to meet its objectives, and subject to influence from its environment.

\section{A Descriptive Model OF THE LIBRARY}

A simple descriptive model of the library is presented as Figure 1 as the basis for further exploratory analysis. The elements of this model have appeared in the foregoing discussion.

A library takes from a bibliographical universe and transmits what it takes through its services to a particular community.

It is in fact caught between two highly demanding environments-its community of users and the bibliographic universe, both of which have proved in the past to be to some degree imponderable. How then does it deal with pressures exerted on it by these environments, come into a viable relationship with a community, and satisfactorily participate in the bibliographic universe? What are the potentialities and limitations inherent in the present structure

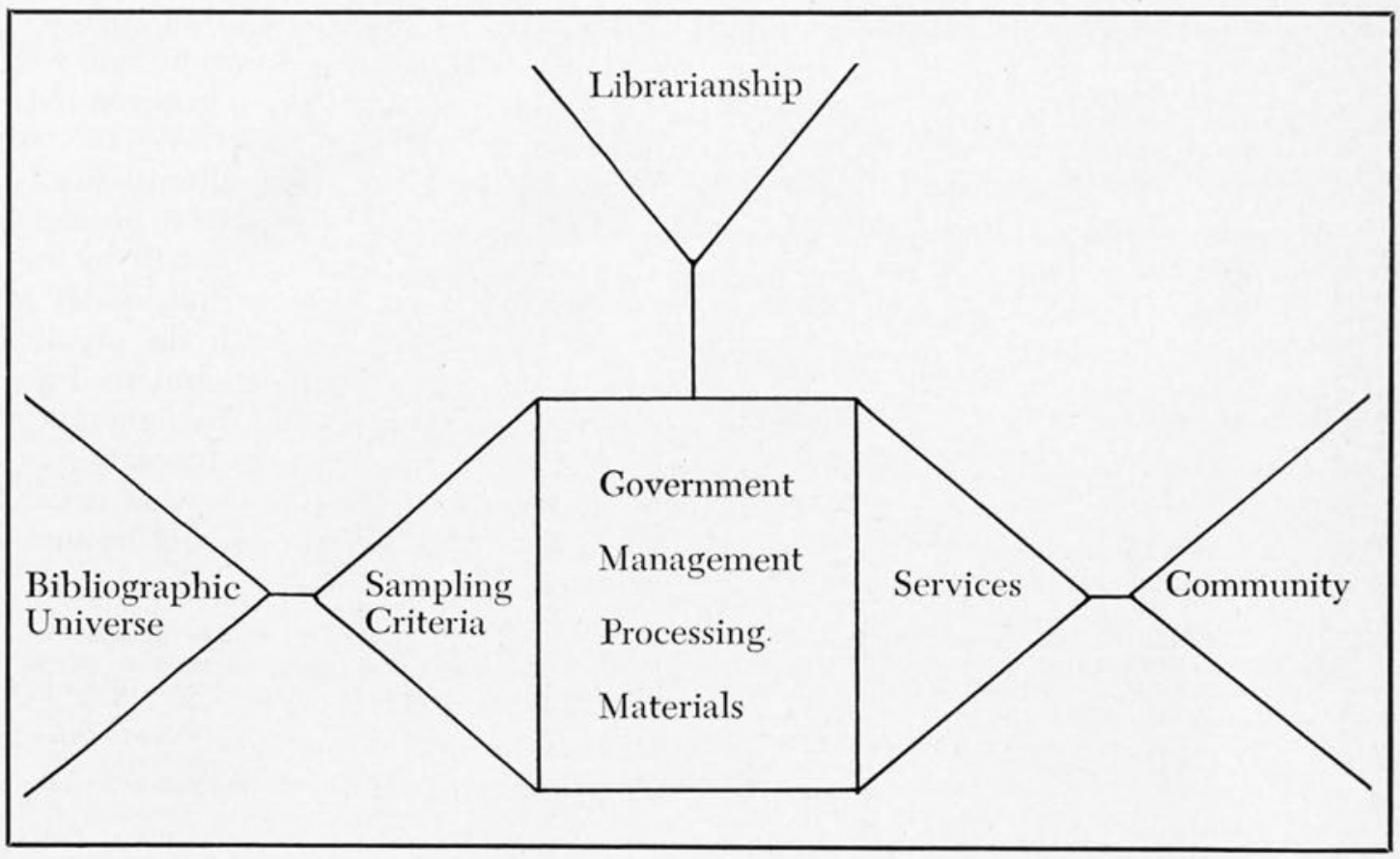

Figure 1 
and process of the library as a formal organization? Can the limitations be transcended by purposeful change, or must new kinds of organizations complement, or even replace, the old? Are its potentialities for the achievement of certain objectives fully and efficiently realized? These are questions to which rather frenetic speculation has as yet provided no answer. What are the implications of the new technology for the library's structure and for the processes going on within it? What are the contemporary effects on its organization of recent forecasts that the future of libraries will be one of complete mechanization? In these allegedly not too far-off days, the library will become part of a complex linkage of computers having enormous memories. These computers will be controlled by programs capable of shelling a book of its bits of information like a bag of peas. The vast data store which will be created from these harvests will be interrogated from various distant points-at any national or even international limit-by the use of television-like consoles and pencils which emit light. ${ }^{22}$ What will the "organism," the library, be like then? It is questions of this kind which one addresses to a model in the hope of some systematic presentation of the problems, in the hope of explanation and ultimately of testable prediction.

\section{The Community}

The nature and importance of the social function of libraries has been the subject for some speculation ${ }^{23}$ because it is here that apologists hope to locate

${ }^{22}$ J. C. R. Licklider, Libraries of the Future (Cambridge, Massachusetts: M.I.T. Press, 1965).

${ }^{23}$ Margaret E. Egan and Jesse H. Shera, "Foundations of a Theory of Bibliography," Library Quarterly, XXII (April 1952), p. 125-37; Pierce Butler, "The Cultural Function of the Library," Library Quarterly, XXII (April 1952), p. 79-91; Pierce Butler, Introduction to Library Science (Chicago: University of Chicago Press, 1961); Jesse Shera, "Emergence of a New Institutional Structure for the Dissemination of Specialized Information," in The Communication of Specialized Information ed. by Margaret Egan (Chicago: Graduate Library School, University of Chicago, 1954), p. 113-28. their justification for a "genuinely independent, academically respectable, and socially beneficial profession." 24 Certainly society must validate the library's claims to service. It is clear, however, that whatever the general function of libraries in society, a specific library fulfills that function within a particular community. Its community, with some oversimplification, is the organization that pays for it. For the library this organization is usually its body of potential users. Ideally, the demand its community makes establishes the operational goals of a particular library and defines the nature of its services. But not completely. The library has a general social warrant by which libraries are libraries and not some other kind of formal organization. Those responsible for a library then may assess the bibliographic needs of a community in a way not equivalent to the demand the community makes on it. In the past librarians frequently have seen the potential of the library as unfulfilled and have continually attempted to make its services more fully appreciated and more widely used.

There is here an interesting problemhow nearly congruous are perceptions of a community's bibliographic demands with assessments of its needs, and what are the organizational implications of incongruity? Presumably incongruity would arise because the library and the community are both goal-directed organizations, and would express itself as conflict between the government of the library (representing the communitythe board of governors, trustees, and so on) and the management of the library (chief librarian and his upper-level staff). Incongruity and conflict may be intensified given a strongly professional orientation in the librarian and his staff, where "professional orientation" means administration or management which emphasizes not so much the institutional dependence of the library, but rather its

\footnotetext{
${ }^{24}$ Jesse Shera, op. cit., p. 128.
} 
participation in what has been here called the bibliographical universe.

If the library's community were clearly bounded, its bibliographic demands and needs specific, known, and predictable over time, then sampling criteria could be unequivocal and the treatment of material obtained from the bibliographical universe could be rationally directed towards specific services agreed upon as fulfilling the library's goals. But the nature of the community, usually changing with some degree of rapidity, is never fully known. Furthermore the library must, in these doubtful circumstances, anticipate demand. The necessity for anticipation raises the spectre of organizational uncertainty and of potential failure in service. A community could demand "perfect" service. Uncertainty would therefore be intolerable, and the library would have to assume that functionally its community was everyone, and that it should obtain everything in the bibliographical universe and process it in every way conceivable in order to meet every possible kind of request. The community would in a sense give the library its head in the belief that it would be best served by an organization into which the whole bibliographical universe was flowing and from which the whole of it could be selectively transmitted. Every request could be met, every service provided. In practice, of course, limits are set-on the one hand by the size and complexity of the bibliographical universe, and on the other by inadequate provision in the community. The library samples the bibliographical universe. What then are the sampling criteria employed by a library? What is their relation to the kinds of service provided and to an assessment of demand and need in the community? The relation of what might be called library autonomy and community tolerance of "bibliographical" uncertainty is an interesting problem, and so is the existence of a relationship between size and autonomy. One might expect that a library, increasing in size, develops a kind of momentum-the longer it grows the more it needs if it is to be prevented from "declining," i.e., that size and autonomy are in some way directly related. One wonders-given different sizeswhat degrees of "autonomy" would maximize the effectiveness of the library in its community. The critical issues here, of course, are: What constitutes "autonomy" and "effectiveness," and how are these to be measured? The plethora of standards of various kinds, for example, are in practice of not much use in determining "effectiveness," though they are a beginning.

There can be no doubt that an important trend in library organization nowadays has been towards autonomy. Partly this is the result of federal funds -nowadays the library is not necessarily entirely dependent financially upon its community. The existence of this external support suggests that there has been a movement of library goals towards a more central position in the value and power system of society generally. ${ }^{25}$ As a source of external funds libraries become directly and indirectly more powerful in their communities, more able to demand their own terms and command the community's funds than before. More and more frequently the limits upon accessibility to the bibliographic universe imposed by a single collection are seen as intolerable and to be transcended. Given the increasing size of the record of scholarship, and the increasing specialism which desires access to ever more specific and narrow areas of it, the effectiveness of any one library in a community of any diversity is apparently reduced. The result has been a growing emphasis on "larger units" of service, which have become effective-to whatever extent that they are effective-part-

\footnotetext{
${ }^{25} \mathrm{~S}$. N. Eisenstadt, "Bureaucracy, Bureaucratization and Debureaucratization," Complex Organizations, ed. by Amitai Etzioni, op. cit., p. 272-3.
} 
ly because of recent developments in technology-especially those related to the computer and its ancillary machinery, and teletype and telefacsimile transmission facilities. Investments in technology and organization to use it effectively have increased the tendencies of libraries to look more steadily outward to the bibliographical universe, to become more widely committed outside their immediate community, to have a wider sphere of influence, to become more autonomous. Nevertheless, the implication of this autonomy is always that the library can only thus become satisfactorily effective in its community.

\section{The Library}

The implications of these new developments towards local, regional, and broader systems for the individual library as a formal organization have not been pursued. Presumably in library systems there will be some centralization of processing and of control by which the activities of particular libraries will be in some ways curtailed and in others extended. The introduction of the newer technology is bound to have far-reaching consequences for the library because it is an organization in which methodological conservatism is inherent. Presumably libraries must install the new equipment and employ those who can use it. As a bureaucracy, the library must face the increasingly difficult problem of incorporation of "technological" specialists into its often fairly rigid hierarchical order. $^{26}$ It already faces the familiar conflict arising from professionality of its members and their organizational loyalty. Usually a library consists of a board of governors or trustees, a managerial professional staff, line professionals (reference librarians, bibliographers, and so on), a large clerical staff, student aids if available, and a janitorial staff. To these are being added consultants and special

\footnotetext{
2 This general problem is seen by Victor Thompson as "the most symptomatic characteristic of modern bureaucracy," Modern Organization (New York: Knopf, 1965 ), p. 6.
}

planning groups. There are considerable problems in task-differentiation between line-librarians and clerks, between what is "professional" and what is not. Much of the work in libraries is repetitive and dull; much of it is supervisory in nature -it is characteristic that the contact of the client with the library staff tends usually to be at the lowest level-with aids, clerks, pages. The introduction of the computer may help solve some of these problems. Presumably much of the clerical work can be taken over by the computer and done more quickly and efficiently by it. Librarians will be able to concentrate on refinements of service, on exceptional cases. ${ }^{27}$ One would expect that the organizational structure in such halcyon days will resemble more nearly the collegial structure described by Parsons and others as likely to supersede the bureaucratic structures typical of present-day, large-scale formal organization. ${ }^{28}$

One rather interesting problem which the introduction of the computer will affect is that of decentralization. In the past as a library or its community grew in size it was decentralized, and branch and departmental libraries were set up. Sometimes these became almost independent, but more usually they were carefully tied to the main library by devices such as budgetary allotments and centralized processing. One of the best known famous systems of decentralized, coordinated libraries is that developed at Harvard. ${ }^{29}$ The advantage of decentralization has been the distribution of the enormous bulk of the library's collections to different places where they could be more easily controlled and de-

\footnotetext{
${ }^{27}$ Don R. Swanson, "Library Goals and the Role of Automation," Special Libraries, CIII (October 1962), p. 466-71.

${ }_{28}$ William Delaney quotes from Parsons and discusses his views on "post-bureaucratic" organization in "The Development and Decline of Patrimonial and Bureaucratic Administration," Administrative Science Quarterly, VII (March 1963), p. 476.

${ }^{20}$ Keyes D. Metcalf, Report on the Harvard University Library, A Study of Present and Prospective Problems (Cambridge, Massachusetts: Harvard University Library, 1955). Paul Buck, Libraries and Universities (Cambridge, Massachusetts: Belknap Press, 1964), p. $87-92$.
} 
veloped in parts than as a whole. Moreover, branches in various areas could be created to satisfy the library needs of various sub-communities within the wider community which the library served. The introduction of the computer with the possibilities it has for completely centralizing processing and circulation control, may make branch and departmental libraries dead storehouses of books with a clerk to register and discharge loans. With the introduction of an automated catalog of the kind envisaged by Swanson, ${ }^{30}$ a catalog which can be interrogated from remote consoles and which automatically registers loans, users, locations, as well as detailed subject information, decentralized libraries may well become things of the past. What would be required would be a highly sophisticated bibliographical headquarters, sufficiently central or at least accessible storehouses, and swift retrieval service.

The trends towards larger systems described above may also be expected to have interesting effects on how the administrative organization of the library deals with conflict. In the past one of the main functions of the director of a library has been to act as a buffer between a lay board of governors and the library, the library being conceived of as an organization with its own goals (represented if you will by the professional expectations-in some degree of conflict themselves-of the library staff.) Conflict of this kind may be thought to have been mainly intra-organizational. Nowadays one assumes that whenever the decision is finally made in a particular library to commit it to a library system-one wonders how the decision is made and how such decisions relate to the vital statistics of libraries and their communities-the role of the board of governors or trustees lessens. Conflict will tend rather to be between various libraries, and between libraries and vari-

${ }^{30}$ Don R. Swanson, "Dialogues with a Catalog," Library Quarterly, XXXIV (January 1964), p. 113-25. ous governmental agencies who locate libraries in the system and then make prescriptions of one kind or another for them. A whole new dimension of conflict would seem to have been opened up.

Little is known about the informal organization of the library-of how the various groups of participants interact with each other to affect the processes of the library. It would be interesting in this context to assess the impact of goal visibility (related to turnover) and different degrees of organizational autonomy, on staff at various levels in the organization. Traditionally the library has been regarded as a rule-dominated bureaucracy. But it is also probably the case that libraries may "feel" their community mainly through complaint. Successful service is normally taken for granted. There is little in the way of praise, but if discontent with service should reach a certain threshold, users complain. Perhaps bureaucratization has been developed partly to absorb complaint in order to protect the staff of the library. The "rule-dominated" conception of bureaucracy, however, may well be justified in certain departments of the library such as the cataloging department. Here work proceeds by taking unique physical items (books and so on), describing them physically and analyzing them for subject-content according to an extremely complicated system of rules. The stereotype librarian is usually a cataloger. This stereotype is one of "bureaupathic" 31 behavior. Just what the incidence of this kind of behavior is and how it is different in different parts of

${ }^{r}$ This term is used by Thompson to discuss the kind of dysfunctional behavior first noted by Robert K. Merton in "Bureaucratic Structure and Personality," in Social Forces, XVIII (May 1940), p. 560-68. Thompson describes it as follows: "Personal behavior patterns are frequently encountered which exaggerate the characteristic qualities of bureaucratic organization. Within bureaucracy we often find excessive aloofness, ritualistic attachment to routines and procedures and resistance to change; and associated with these behavior patterns is a petty insistance upon rights of authority and status. From the standpoint of organizational goal accomplishment, these personal behavior patterns are pathological because they do not advance organizational goals," op. cit., p. 152-53. 
the library, and if and how and why it has begun to change is not known. In this context, it is interesting to note that one much publicized mechanized system $^{32}$ has failed-without publicity-under rumored conditions suggesting not merely faulty planning and insufficient support, but also subtle intra-organizational resistance ${ }^{33}$ which may very well express the power of the informal organization of the library.

\section{The Bibliographic Universe}

If the problem of the library vis-à-vis its community is: Who are its users, and what do they want? Its problem vis-à-vis the bibliographic universe is: What does the universe contain, and what can the individual library supply from it? These questions cannot be answered simply; for one thing, it seems that the bibliographic universe and the library's community are in some frenzy of change, whether real or partly imaginary it is hard to say. The problem becomes one of determining what is going on in the bibliographical universe and how the library is related to it.

One might begin an analysis of this problem by distinguishing information and its communication. Let us suppose that the bibliographical universe consists of information being transmitted in a variety of channels. The analogy of a communications system is useful-information, messages, channels, noise, and redundance. Various channels receive and transmit information according to the way it is encoded. Certain channels can handle greater volumes of information; certain channels handle information at greater speed than others. It is fair to say also that as the volume of in-

\footnotetext{
32 Edward Heiliger, "Florida Atlantic University; New Libraries on New Campuses," CRL, XXV (May 1964), p. 181-85; and Edward Heiliger, "Staffing a Computer Based Library," Library Journal, LXXXIX (July 15, 1964), p. 2738-9.

${ }^{33}$ Harrison Bryan, "American Automation in Action," Library Journal, XCII (January 15, 1967), p. 189-96.
}

formation has increased so has the variety of channels to deal with it, and if Haire's analogy holds, at an even greater rate-that is to say, with increased size, goes an even more rapidly increased supportive complexity. The notion of channel, however, may be interpreted to mean organization, and the bibliographic universe may be seen to consist of a vast quantity of information, encoded in a variety of ways, being handled by a variety of organizations.

The real problem facing the modern library may well be not the size and complexity of the bibliographic universe (which undeniably has increased dramatically), but the nature and capacity of the other organizations in it (which have also increased dramatically in numbers and functions), organizations with which the library has to draw itself into some functional relationship. Failure to identify these organizations-both by the library and the library's community, has led to noise and distortion as various channels are forced to attempt to deal with information not appropriate to them. Certainly if there is change in the bibliographical universe and in the communities which draw on it, and revolutionary changes in bibliographical technology, then all organizations involved in the universe and employing the technology must themselves be in a state of some flux. The best that can be hoped for is an accurate analysis of present conditions and a satisfactory rationalization of them and of organizational prescriptions based on them.

It is possible to identify some of the organizations by which information is transmitted in the bibliographical universe, and so with which libraries must seek some non-competitive complementary relationship. Some of these organizations have emerged to handle new "forms" of literature, but all serve to introduce into the bibliographic universe 
a complexity different from the original problem of sheer bulk which they were created to mitigate. That is to say, they complicate the problem to which they provide partial solution. Perhaps the most remarkable of these organizations, whose importance has been previously much underestimated, are informal groups of scientists. These have been called "invisible colleges," 34 and have been identified as extremely important to scientific communication in a number of different fields. ${ }^{35}$ Swanson has suggested that they be brought to a stage of "translucence" for study and for formalization to whatever degree is necessary to maximize their effectiveness. ${ }^{36}$ As well as the not fully understood system of relatively informal communication, which certainly would seem no essential business of libraries, there are a number of document handling organizations. Documentation centers and a supporting intellectual endeavor called "Documentation" developed in the early years of this century in Europe to deal with a very general class of bibliographical items called "documents" as opposed to more traditional library materials. ${ }^{37}$ As organized research, especially that which is government supported, has become widespread and has produced a vast mass of progress and research reports together with technical notes and papers, so a great many document centers have appeared to deal with them. This material is not always published in a formal way, or not without much delay. Its existence and use was seen as having become

${ }^{34}$ J. Derek de Solla Price, Little Science, Big Science. op. cit., p. 62-91.

${ }^{35}$ William D. Garvey and Belver C. Griffith, "Scientific Information Exchange in Psychology," Science, CXXXXVI (December 25, 1964), 1658.

${ }^{36}$ Don R. Swanson, "On Improving Communication Among Scientists," Bulletin of the Atomic Scientists, XXII (February 1966), 8-12.

${ }_{37}$ These ideas were first developed by Paul Otlet and Henri LaFontaine and were embodied in the work of the Institut International de Bibliographie which was set up in 1895. See W. Boyd Rayward, "UDC and FID - an Historical Perspective," Library Quarterly, XXXVII (July 1967), 259-78. an important problem as early as 1952 when the Graduate Library School's annual conference at the University of Chicago was devoted to it. ${ }^{38}$ The documentation centers dealing with it are usually-naturally enough-connected with government. The Defense Documentation Center and the Scientific and Technical Information Facility of NASA are two important examples. Simpson and Flanagan give others. ${ }^{39}$ Such centers often prepare bibliographies and provide abstracting and indexing services for their materials.

Perhaps one of the most important though still imperfectly understood kinds of organization to emerge recently is the Information Center. Impetus to the establishment of these centers was given by the Weinberg report. ${ }^{40}$ Information centers deal with highly specialized subject fields and provide active services of indexing, abstracting, preparation of demand and recurrent bibliographies, selective dissemination of bibliographic information, and substantive answers to inquiries-information, not documents. Simpson and Flanagan call them Information Analysis Centers. ${ }^{41}$ They are characterized by the use of technically qualified personnel, of sophisticated information machinery, of documents of one kind or another from a wide variety of sources (in contradistinction to the government documentation centers), and often in analysis provide useful data compilations, state of the art reviews, and so on. ${ }^{42}$ Weinberg, four years after his report exploded into the bibliographical universe, observes that "the informa-

\footnotetext{
${ }^{38}$ Margaret E. Egan, ed. The Communication of Specialized Information (Chicago: University of Chicago Graduate Library School, 1954).

${ }^{39}$ G. S. Simpson and C. Flanagan, "Information Centers and Services," in Annual Review of Informa tion Science and Technology, vol. 1. (New York: Interscience, 1966 ), p. 309.

${ }^{40}$ President's Science Advisory Committee. Science, Government and Information (Washington, D.C.: The White House, 1963).

${ }_{41}^{4}$ G. S. Simpson and C. Flanagan, op. cit., p. 321.

${ }^{42}$ Ibid., p. 323.
} 
tion center, which was viewed as crucial in the PSAC report .... is proving to be a dominant element in the new information system." 43

Other organizations, however, are emerging to play a critical part in the "new" information system. They are scientific professional associations, government agencies, even new kinds of libraries and a relatively new phenomenon: "information" corporations of one kind or another-The Institute for Scientific Information (which has the "all-consuming goal" of organizing "the World's total output of significant scientific and technical literature into an integrated file!") ${ }^{44}$ Documentation, Inc., Arthur D. Little, Inc., and so on. The National Library of Medicine has an automated storage and retrieval system called MEDLARS ${ }^{45}$ which provides recurrent and demand bibliographies from the literature of medicine; Chemical Abstracts is introducing a similar system for the literature of chemistry. ${ }^{46}$ Most of the important indexing and abstracting services are providing regular, often computer-based, indexes in a wide variety of fields. The Science Citation Index is a novel and useful development in bibliographical control. Many services are available on microfilm especially coded for rapid and convenient use in automatic machines.

The problem then is how these various services are related. Most of them deal with a specialized literature, in a specialized way with a particular emphasis on science and technology, and on speed in the provision of information. A dis-

${ }^{43}$ Eugene Garfield, "Information Retrieval" (Report of meeting of AAAS in Washington, D.C., December

27, 1966), Science, CLVI (June 6, 1967), 1400.

"4 ISI Eases Scientists Information Problems.

(Advertisement) Science, CLIV (November 11, 1966), 762-63.

is U.S. Department of Health, Education and Welfare. The Medlars Story at the National Library of Medicine (Washington, D.C.: The Department, 1963); Charles J. Austin, The Medlars System: An Application Report (Washington: Public Health Service, (1964), p. 28-31.

${ }^{46}$ Simpson and Flanagan, op. cit., p. 314. cipline of sorts, "information science and retrieval," has developed around them, displacing or incorporating the earlier "documentation." It deals with the potentialities of the new computer technology, and with an "intellectual crisis" feelingly described by Overhage. ${ }^{47}$ This discipline has developed its own professional association which has been urged to accept fuller and fuller responsibility for its "body of scientific knowledge and maturing technology." 48 Libraries are little considered in this context, especially general research libraries or public libraries whose concerns are not intensely specialized or limited. It may well be, however, that the "new information system" has crystallized sufficiently for the role of various kinds of libraries to be distinguished in it. It would seem necessary as a first step to arrive at some taxonomy of information services and the kinds of organization best suited to supply them.

\section{Towards Measurement}

So far a crucial problem in providing some sort of reliable answer to the various questions raised above has been avoided. The problem is methodological. How is the foregoing discussion with its descriptive orientation and a priori theorizing to be put into the rigorous form demanded by the scientific method? Operational definitions for the variables discussed above and for others which may be suggested by a consideration of the library in terms of various models to be found in the literature of organizations, must be attempted. Hypotheses about the relations of the variables and testable deductions from the hypotheses must be made. These must be confirmed

\footnotetext{
47 Carl F. Overhage, "Science Libraries: Prospects and Problems," Science, CLV (February 17, 1967), 803.

${ }^{45}$ Louise Schultz, "The Information System: Too Big and Growing," American Documentation, XIII (July 1962), 293.
} 
(or not) by the performance of test, and these tests, to be successful, must in their turn lead to the refinement of the definitions, reformulation of the hypotheses, new deductions, and revision and repetition of the tests. It is not the purpose of these concluding paragraphs to attempt the solution of the general methodological problem or to set out a systematic research plan, but rather to suggest possible approaches to some of the general concepts employed in the paper, particularly goals and performance effectiveness.

There are two major questions immediately suggested by the realization that an organization has goals. The first is: what are the organization's goals? The second is: how nearly does the organization meet or fulfill its goals? Obviously one cannot begin to examine the second question without some definite answer to the first. This second question raises the problem of performance effectiveness. Efficiency, one may note in passing, is rather different, being expressed in terms of judgments about the disposition of means in the organization in relation to its end-products; and not primarily about goals towards the most efficient fulfillment of which the organization as an on-going system is directed. One must also recognize that there are at least three general kinds of goals to be considered. The first kind is personal goals-expressible in terms of a desire to be interested by one's wish for influence, power, status, and so on which participants may partly fulfill by using the organization as a means. Another is the goals held for the organization by the various kinds of participants in it, and these may be expected to vary according to the location of the participants in its structure. The question, "what are the organization's goals?" can be reformulated to become "how much of whose goals are we to consider as the organization's goals?" One may obtain through sampling and interview techniques some idea of what people at various levels in a library, or in many libraries, consider to be the most general goals of libraries; the future goals of their library; its immediate goals; the goals of their section in it and of their own professional activity. If these goals are described as ostensible or public goals, a third kind of goals may be described as real, private, or even as system goals. These are the goals the library or groups of its personnel may be said actually to operate by at any given moment. They are arrived at by inference-inviting the accusation of the post hoc, ergo propter hoc fallacy. One way of obtaining some objective account of them is through a content analysis of directives issued by the principal librarian and other executives to the library staff, or of the minutes of trustees meetings and so on.

The attempt to distinguish the various kinds of goals, to identify them objectively and to differentiate their effects may well be regarded as an attempt on a conceptual Pandora's box. ${ }^{49}$ The recognition that an organization's goals are not single or simple, but composite and complex is necessary to an understanding of organizational dynamics. It also suggests the need for composite and complex measures or indicators of performance effectiveness. In a sense degree of goal correlation may itself be one such an indicator, especially if the distinction between ostensible and "real" goals can be maintained. If the correlation were perfect the organization would be doing what everyone participating in it wanted. Effectiveness, that is to say, can at least be approached subjectively.

\footnotetext{
49 One such attempt has been made by M. D. Mesarovic, J. L. Sanders, C. F. Sprague in their "An Axiomatic Approach to Organizations from a General Systems Viewpoint," in New Perspectives in Organization Research, op. cit., p. 493-512.
} 
Those who have certain goals with respect to an organization should know how well it has achieved them.

Measures of effectiveness derived from user or (more generally) participant satisfaction have been described as aggregative subjective measures. Attempts to obtain more objective measures for libraries have not generally been successful. Librarians have placed much faith in the statistics of expenditure, collections, and use for determining how successful a library is, but such statistics need to be interpreted with reference either to an ideal set of statistics (established in some a priori fashion) or to similar statistics derived from the same organization at an earlier point in time or from a sampling at a given point in time over a number of similar organizations. The general problem in the use of statistics is to determine the relationship of things that can be "counted" to the underlying goal structure of the organization. Conclusions about goal fulfillment made on the basis of the kinds of statistics now collected may, in fact, be quite misleading.

It is possible, perhaps, that other kinds of objective measures of performance effectiveness may be adapted from those developed in recent years in the field of information retrieval. Such measures may be described as behavioral or "systemic." Organizational behavior culminates in the performance of certain important, recurring, idiosyncratic actions. Libraries supply books, periodical articles, and so on in response to requests for them specifically or for information on subjects. Behavioral measures of performance would attempt to assess the effectiveness of these actions. In the AslibCranfield experiments in England, recall and relevance ratios were developed to measure the relative effectiveness of per- formance of different information retrieval systems. ${ }^{50}$ Perhaps modifications of these ratios might be made for use in the evaluation of libraries. Practical measures derived from such theoretical notions might stress the irrelevant material recalled from the system in response to a request, and (perhaps on the basis of a small sample) relevant material missed. Cooper suggests that the effectiveness of an information system be measured by the amount of material that has to be discarded before a client judges his request to have been satisfied. ${ }^{51}$ While ever the highly subjective notion of relevance has to be maintained for these measures, their usefulness in practice will be severely limited. One may hope, however, that an objective correlative for relevance may one day be found.

This discussion has suggested three tentative and partial approaches to an assessment of performance effectiveness: aggregative subjective measures, statistics of use, and "behavioral" measures of characteristic actions. Together these give us a fuller picture than any particular one would separately of how well the organization is meeting its various and many goals. In attempting to take into account the variety of goals and ordering them according to a system of priority (obviously some goals are not as important as others), one might suggest the possibility of obtaining some kind of effectiveness profile for an organization. An effectiveness profile of a library (or indeed of any organization) would be a valuable descriptive and diagnostic tool.

5o Cyril W. Cleverdon, Report on the Testing and Analysis of an Investigation into the Comparative Efficiency of Indexing Systems (Cranfield, England: Aslib Cranfield Research Project, 1962).

${ }^{51}$ William S. Cooper, "Reduction of Expected Search Length as a Criterion of Retrieval Effectiveness, American Documentation, XIX (January 1968), 30-41. 